\title{
Automated Cobb Angle Measurement for Adolescent Idiopathic Scoliosis Using Convolutional Neural Network
}

\author{
Wahyu Caesarendra ${ }^{1, * \mathbb{D}}$, Wahyu Rahmaniar ${ }^{2} \mathbb{D}$, John Mathew ${ }^{3}$ and Ady Thien ${ }^{3, *}$ \\ 1 Manufacturing Systems Engineering, Faculty of Integrated Technologies, Universiti Brunei Darussalam, \\ Jalan Tungku Link, Gadong BE1410, Brunei \\ 2 Department of Electronic Engineering, National Taipei University of Technology, Taipei 10608, Taiwan; \\ wahyu.rahmaniar@gmail.com \\ 3 Department of Neurosurgery, Brunei Neuroscience, Stroke and Rehabilitation Centre, Pantai Jerudong \\ Specialist Centre, Jerudong BG3122, Brunei; dr.johnmathew@pjscbrunei.com \\ * Correspondence: wahyu.caesarendra@ubd.edu.bn (W.C.); ady.thien@pjscbrunei.com (A.T.)
}

Citation: Caesarendra, W.

Rahmaniar, W.; Mathew, J.; Thien, A. Automated Cobb Angle

Measurement for Adolescent

Idiopathic Scoliosis Using

Convolutional Neural Network.

Diagnostics 2022, 12, 396. https:/ /

doi.org/10.3390/diagnostics12020396

Academic Editor: Christoph Palm

Received: 2 December 2021

Accepted: 31 January 2022

Published: 3 February 2022

Publisher's Note: MDPI stays neutral with regard to jurisdictional claims in published maps and institutional affiliations.

Copyright: (C) 2022 by the authors. Licensee MDPI, Basel, Switzerland. This article is an open access article distributed under the terms and conditions of the Creative Commons Attribution (CC BY) license (https:// creativecommons.org/licenses/by/ $4.0 /)$.

\begin{abstract}
The Cobb angle measurement of the scoliotic spine is prone to inter- and intra-observer variations in the clinical setting. This paper proposes a deep learning architecture for detecting spine vertebrae from $X$-ray images to evaluate the Cobb angle automatically. The public AASCE MICCAI 2019 anterior-posterior X-ray image dataset and local images were used to train and test the proposed convolutional neural network architecture. Sixty-eight landmark features of the spine were detected from the input image to obtain seventeen vertebrae on the spine. The vertebrae locations obtained were processed to automatically measure the Cobb angle. The proposed method can measure the Cobb angle with accuracies up to $93.6 \%$ and has excellent reliability compared to clinicians' measurement (intraclass correlation coefficient $>0.95$ ). The proposed deep learning architecture may be used as a tool to augment Cobb angle measurement in X-ray images of patients with adolescent idiopathic scoliosis in a real-world clinical setting.
\end{abstract}

Keywords: convolutional neural network (CNN); deep learning; scoliosis; spine classification; vertebrae

\section{Introduction}

Scoliosis is a structural abnormality in which the spine curves from side to side and rotates. Children aged 10 to 17 years old who present with scoliosis of unknown cause are categorized as having Adolescent Idiopathic Scoliosis (AIS) [1]. Patients with mild deformities are usually asymptomatic. However, if the curvature progresses during the growth spurt, discomfort, pain, and symptoms related to abnormal chest wall growth and difference in shoulder height can lead to decreased quality of life [2]. AIS can cause respiratory symptoms, such as shortness of breath when the curvature exceeds $50^{\circ}$, and patients are at a high risk of significant lung function abnormalities if the curvature is more than $100^{\circ}$ [3].

The Cobb measuring method is the gold standard used in quantifying the scoliotic curve. The Cobb Angle (CA) is measured from the most tilted vertebra (end vertebra) above and below the apex (most laterally placed vertebra) of the curve on radiographs taken either in the anterior-posterior or the posterior-anterior view on the coronal plane [4]. In general, the "manual" procedure requires lines to be drawn onto a hardcopy of radiographic films, and the angle between the two lines is measured with a protractor. Therefore, measuring the CA can be time-consuming and is also prone to inter-observer and intraobserver variations. Reported accuracies of measuring CA vary from $2^{\circ}$ to $11^{\circ}[5-7]$, with measurements differing up to $5^{\circ}$ even with the same end vertebrae selected $[2,8]$.

Semi-automatic assessments of CA have been made possible with the advent of the digitalization of computerized radiography. The Picture Archiving and Communications System (PACS) enables a built-in function so users can digitally draw lines for the required 
vertebra, and the system will automatically measure the CA. This method has been proven reliable and has less variation than the manual method [7,9]. However, this method is still dependent on the user selecting the appropriate end vertebrae manually.

With the advancement of computer vision technology [10], such as machine learning [11,12] and deep learning methods [13-15], a fully automatic process to measure the CA quickly and precisely can potentially overcome the shortcomings mentioned above. Digitalized X-ray images, processed through computerized learning, have previously been used to screen, diagnose, and classify severity of scoliosis [12]. Further development in deep learning has also led to an increase in different measuring and assessing CA [13-16]. Automatic detection of the spine anatomy in X-ray images to select the appropriate end vertebrae is an essential stage for CA measurement. Studies on the vertebrae and spine detection based on machine learning [11,12] and deep learning methods [13-16] have been previously reported. However, automatic detection of the vertebrae in X-ray images can be difficult due to overlapping rib and pelvic shadows, as well as contrast differences between the different vertebrae levels. Convolutional neural network (CNN) architecture has been previously shown to help overcome this problem [17].

In this paper, we propose a CNN method for the automatic detection of spinal vertebrae and the measurement of CA in X-ray images. The proposed Automated CA Measurement Method (ACAMM) is assessed for accuracy and reliability compared to clinicians' CA measurements.

\section{Materials and Methods}

This study used two datasets which were comprised of open-source and local data. CNN was used for automated spinal detection and CA measurement. A total of 551 X-ray images were evaluated; 481 and 70 X-ray images were used for training and testing stages, respectively. For ease of calculation, the collected data were divided into (1) $\mathrm{CA}<10^{\circ}$; (2) $\mathrm{CA} 10^{\circ}$ to $25^{\circ}$; (3) $\mathrm{CA}>25^{\circ}$ to $40^{\circ}$; and (4) $\mathrm{CA}>40^{\circ}$.

A detailed description of the datasets and the methods are presented in the following subsections.

\subsection{Opensource Datasets}

The collection and labeling of spinal images were performed by the public AASCE MICCAI 2019 anterior-posterior X-ray images dataset [18]. The input images vary in size from $359 \times 973$ to $1427 \times 3755$. Some challenging images can be handled due to our large number of training image conditions, which include images with different noise, contrast, lighting conditions, and spines with high CA, as shown in Figure 1. Each image contains 17 vertebrae from the thoracic (upper spine) and lumbar (lower spine) regions. The image input resolution is set to $1024 \times 512$ for the algorithm development. Each vertebra is located by four corner landmarks. The ground-truth of the 68 landmarks or points in each image is provided by the dataset. 


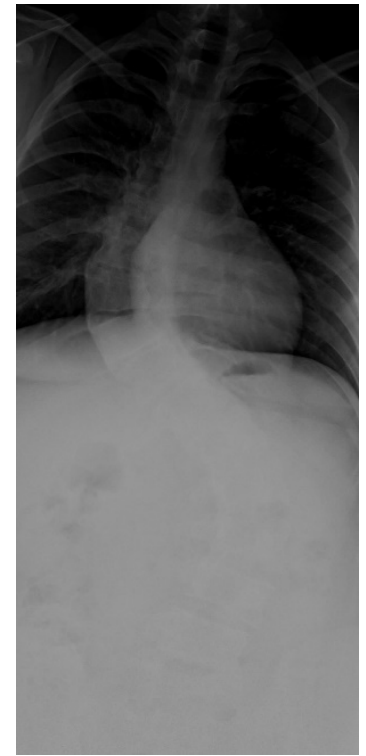

(a)

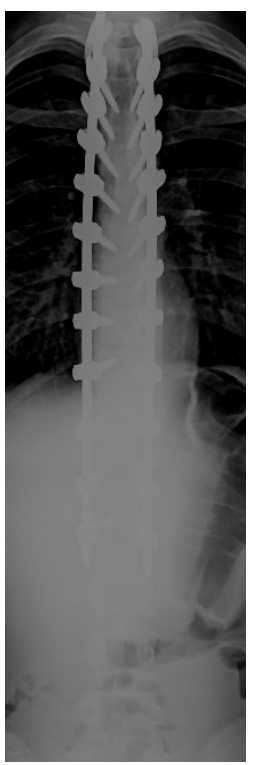

(b)

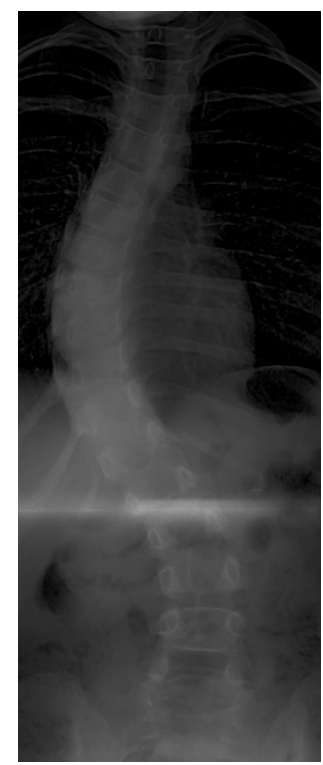

(c)

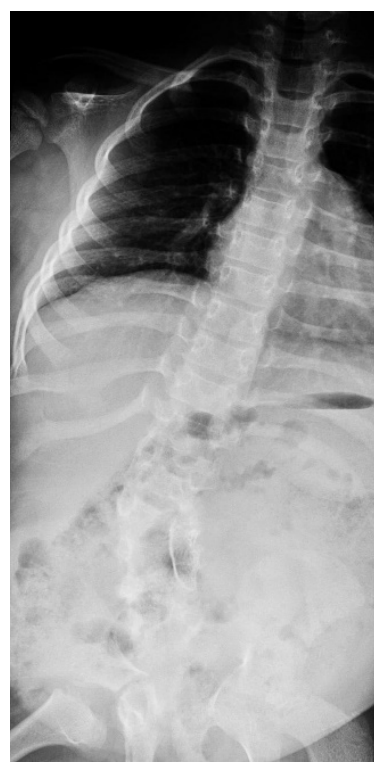

(d)

Figure 1. Examples of some challenging image conditions: (a) Image with noise; (b) high contrast image; (c) low light image; (d) spine with high CA.

\subsection{Local Datasets}

Patients with AIS who attended the scoliosis clinic at Pantai Jerudong Specialist Centre from 1 November 2018 to 4 September 2020 were identified from the institution's scoliosis database. These patients had standard standing anterior-posterior X-rays showing cervical vertebra level 7 to the femoral heads and the entire rib cage from right to left as part of routine clinical management. The $X$-ray images were retrieved from the institution PACS, anonymized, and exported as a JPEG format image, as shown in Figure 2. The CA for each $X$-ray image was measured by (1) two neurosurgeons (Observer 1 specializes in scoliosis; Observer 2 does not), who were blinded to each other and the ACAMM, using the in-built function in the PACS and (2) the ACAMM.

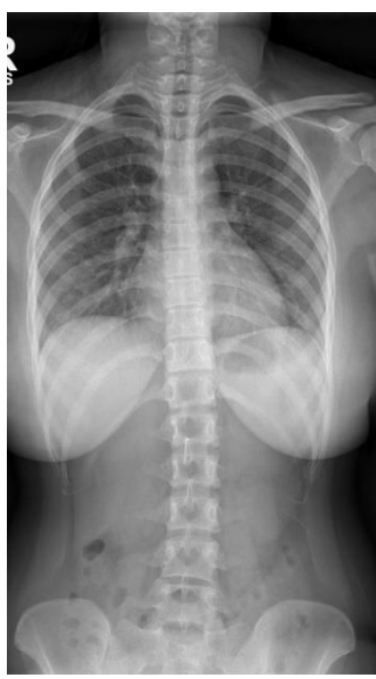

(a)

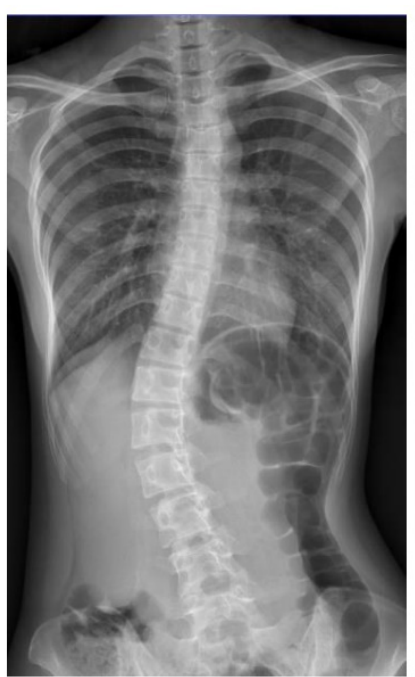

(b)

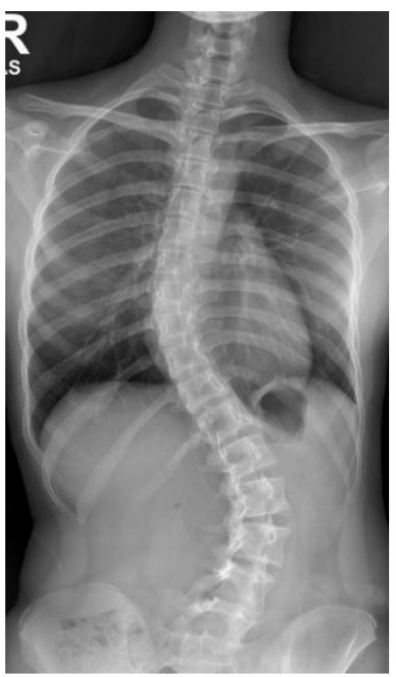

(c)

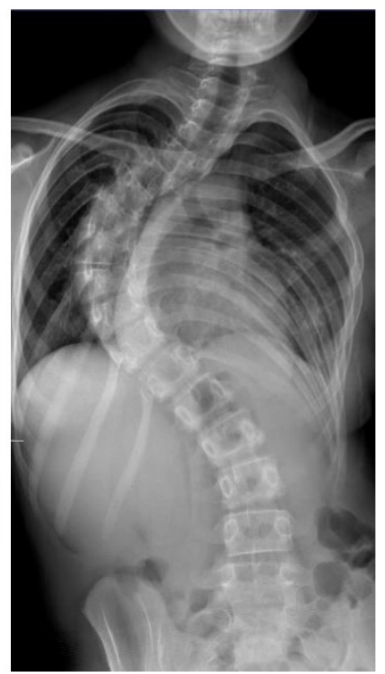

(d)

Figure 2. Examples of standard X-ray images exported from the PACS: (a) CA $<10^{\circ}$; (b) CA $10^{\circ}$ to $25^{\circ}$; (c) $\mathrm{CA}>25^{\circ}$ to $40^{\circ}$; (d) $\mathrm{CA}>40^{\circ}$. 


\subsection{Proposed Methods}

The proposed automated vertebrae detection and CA measurement comprises of sequential stages presented in detail in Figure 3.

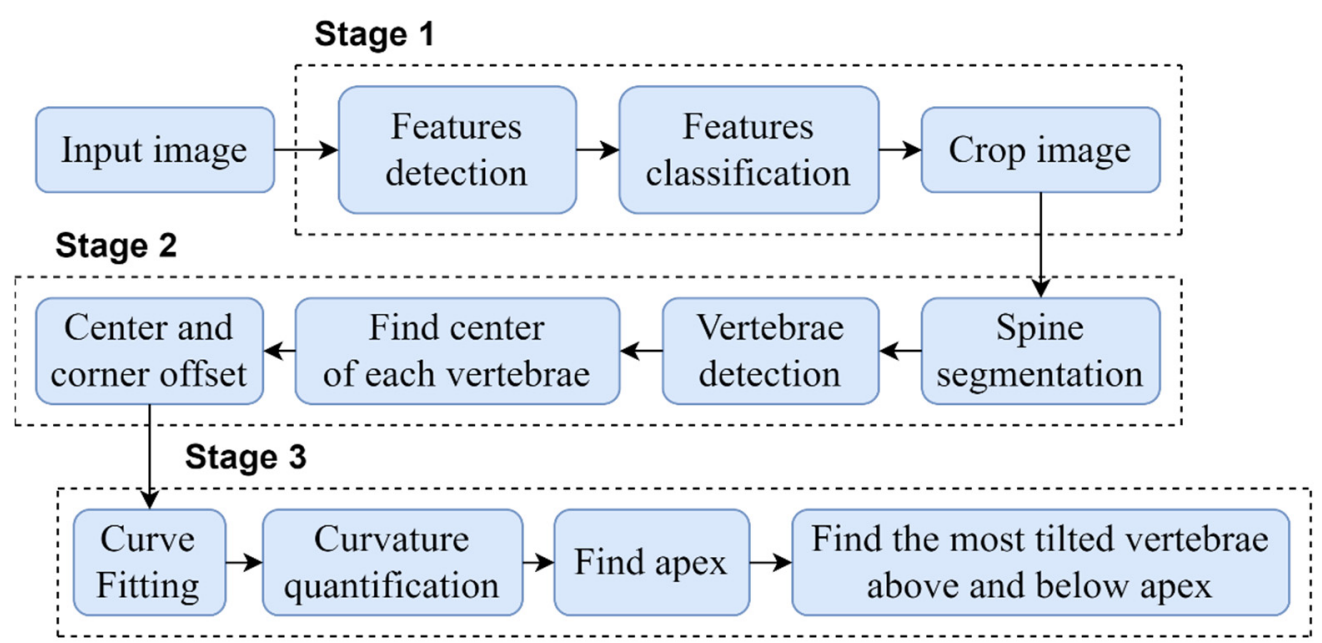

Figure 3. A block diagram of the proposed method.

In order to automate the CA measurement, this study was performed in three main stages: (1) development of an algorithm to automatically crop and standardize the X-ray images dimension; (2) development of vertebrae detection based on the local X-ray images using CNN which improved the previous method described [19,20]; and (3) development of an algorithm to identify the apex vertebra and superior and inferior end vertebrae to measure the CA. The following subsections provide a detail description of the three main stages.

\subsubsection{Stage 1: Pre-Processing of the X-ray Images Size}

Local Binary Patterns (LBP) and cascade classifier [21], a type of visual descriptor used for classification in computer vision, was used to standardize the X-ray images and automatically crop the image between the cervical and sacrum. An example of the process result is shown in Figure 4.

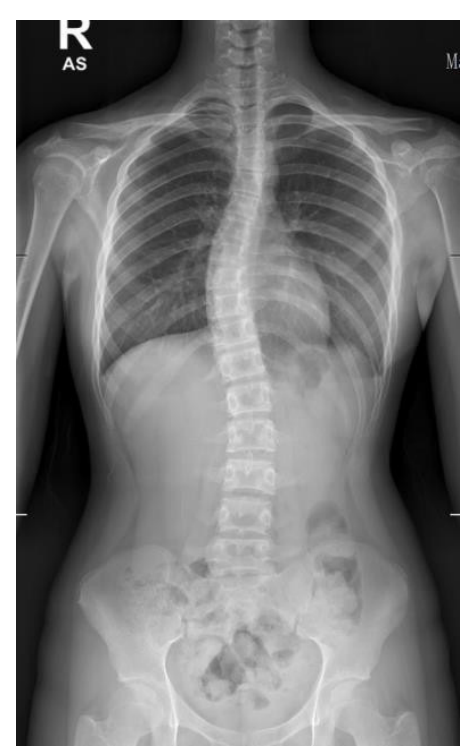

(a)

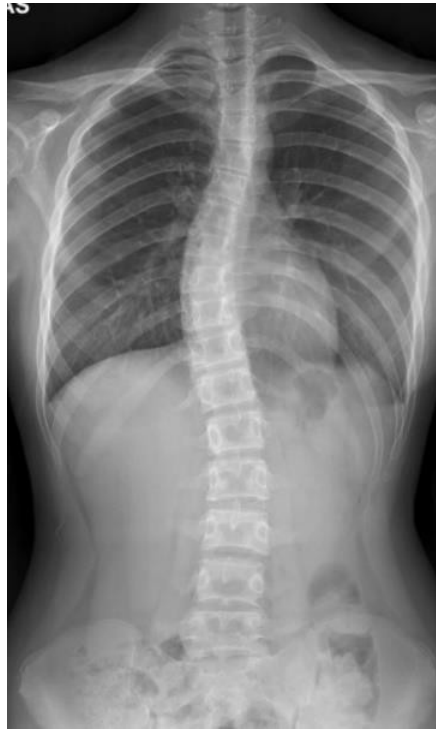

(b)

Figure 4. Pre-processing of the $X$-ray image: (a) original; (b) post-processing. 
The LBP code label histogram contains information about the pixel level distribution for edges and other local features in the image. This feature was chosen because it uses a derivative pattern to obtain direction from a binary gradient, making it suitable for obtaining information from $X$-ray images that have a gray-scale color. Following this, a cascade classifier is used to select features from the X-ray image that are used to define the body area of the object. This body region is selected and used as a positive input for training the cascade classifier. The limits of the boundaries were from cervical vertebrae level-7 to the sacrum at the lumbar-sacral junction, and the right and left outermost parts of the body. The negative image which is separate from the body region of interest is also obtained. The pixel information which contains about body region can be labeled as

$$
L B P_{s, r}\left(N_{c}\right)=\sum_{s=0}^{s-1} g(z) 2^{s}
$$

where $z=N_{s}-N_{c}, s$ is the number of sampling points in a small circular neighborhood with $r=1, N_{s}$ is the neighborhood pixels in each $s, N_{c}$ is the neighborhood center pixel, and the binary threshold function $g(x)$ can be defined as

$$
g(z)= \begin{cases}1, & z \geq 0 \\ 0, & z<0\end{cases}
$$

This body region is then detected by the sliding window method and each area traversed by each sub-window is labeled as positive or negative, can be represented as

$$
L(X)= \begin{cases}1, & \text { if } \sum_{i=1}^{I}\left[\alpha_{i}(X) \times \log \left(\frac{1}{\beta_{i}}\right)\right] \geq \frac{1}{2} \sum_{i=1}^{I} \log \left(\frac{1}{\beta_{i}}\right) \\ 0, & \text { otherwise }\end{cases}
$$

where $X$ is a set of the training images, $\alpha$ is the weight vector, $\beta$ is the weighting parameter which computed from the error associated with the classifier, $i=1,2, \ldots, I$ is the iteration number of the training. If the classifier detects the label as positive, the detection is passed to the next stage. Continuation of the classifier until the final stage will enable the production of a body region to be used as an input image in the next stage.

\subsubsection{Stage 2: Vertebrae Detection on the Local X-ray Images Using CNN}

The deep learning architecture was based on CNN for automated spine segmentation to select the vertebrae accurately and determine the center and corner offset of each vertebra based on a method described previously [19]. Modifications in the pre-processing method and parameter selection were performed according to local datasets. In addition, we improved upon the previous method to enable the automatic CA measurement.

In the proposed method, the 152-layer ResNet [22] is used as a backbone network to classify 68 landmarks to obtain the corner offset of spine. This CNN [23-25] consists of several convolutional layers that learn the local features of the images and generate the classifications. A bottleneck block with 4-layer extension and 152 layers was built using more 3-layer blocks for higher accuracy [26,27]. Despite having increased layers, this backbone has a lower complexity than the ResNet-50 used in the previous method [19]. This feature map is then classified into a fully connected layer with a sigmoid function to get a better feature intensity. The proposed network as presented in Figure 5 includes pooling layers (average pool and maximum pool), feature maps classification (fully connected layer and sigmoid function), and corner offset. The model is initialized from the pre-trained weights on ImageNet. The network was trained to a learning rate of $0.0001 \mathrm{using}$ the Adam optimizer; the batch and epoch sizes were set as 2 and 150, respectively. 


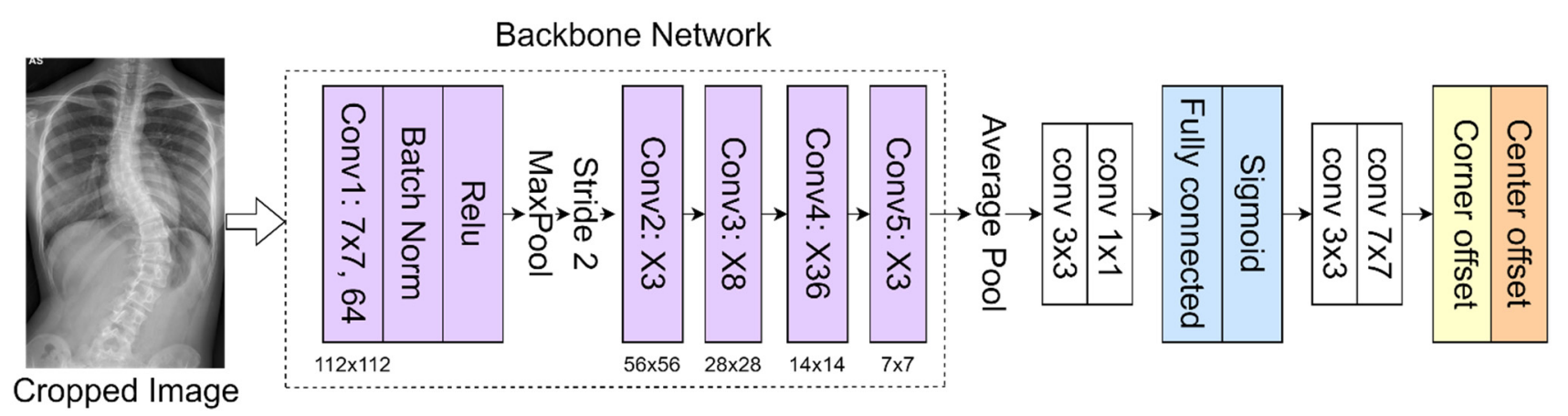

Figure 5. Vertebrae detection network.

The parameters to obtain the classification were optimized using the focal loss [19] as follows:

$$
\text { Loss }=-\frac{1}{M} \sum_{m=1}^{M} \begin{cases}\left(1-\rho_{m}\right)^{2} \log \rho_{m} & , \tau_{m}=1 \\ \left(1-\tau_{m}\right)^{4}\left(\rho_{m}\right)^{2} \log \left(1-\rho_{m}\right) & , \text { otherwise }\end{cases}
$$

where $m=1,2, \ldots, M$ is the index of each feature maps' position, $\rho_{m}$ and $\tau_{m}$ are the prediction and ground-truth value, respectively.

The center offset and corner offset maps using convolutional layers for landmark localization were constructed. Since the output of the feature map on the network is downsized, the center offset and corner offset are mapped to a new location which is then trained with L1 loss. Detection bounding boxes were displayed on each vertebra after applying the object detection step on the X-ray images. The coordinates for the corners and center of each bounding box were found as presented in Figure 6 .

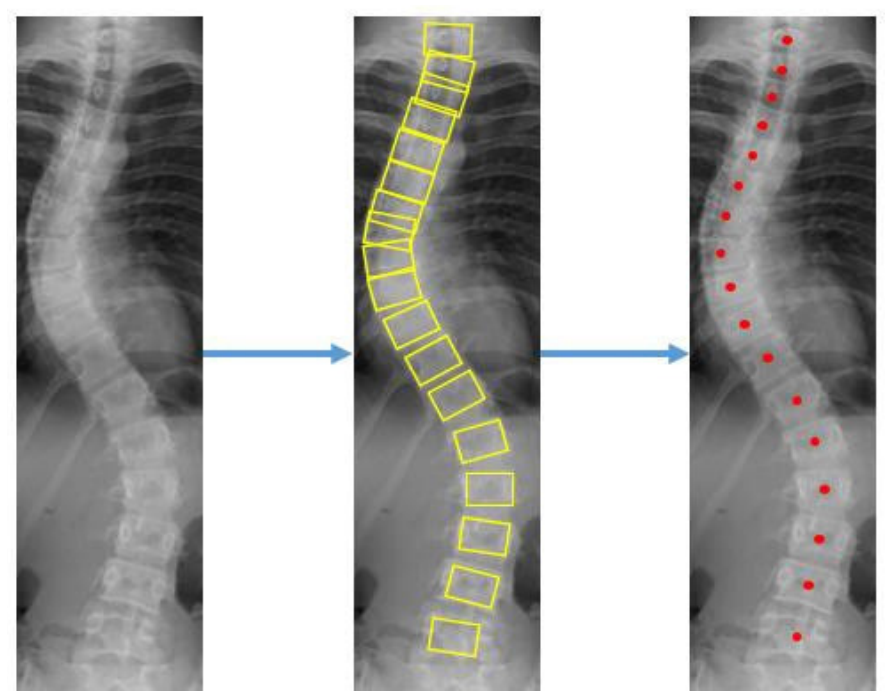

Figure 6. Progressive results of the vertebrae detection to get the location of 4 corners and a center.

Errors in the detection of landmarks in the vertebrae are evaluated by

$$
\varepsilon=\frac{1}{T} \sum_{t=1}^{T}\left\|\left(d_{x, t}, d_{y, t}\right)-\left(p_{x, t}, p_{y, t}\right)\right\|_{2}
$$

where $d$ and $p$ are the locations $(x, y)$ of the detected and ground-truth landmarks, respectively, $t=1,2, \ldots, T$ is the total number of the detected landmarks. 


\subsubsection{Stage 3: Cobb Angle (CA) Measurement}

Curve fitting was used to select the appropriate boxes. Boxes with a prediction score of more than 0.5 were extracted. From the location of the detected boxes, the center point of each vertebra is found to remove some outliers based on the anatomy of the spine, where the adjacent vertebrae should not be far apart from each other. If the $x$-axis center of the detected bounding box is more than half the width of the box from the $x$-axis center of its two closest neighbors (top and bottom), the box is rejected as an outlier. Otherwise, the position of the box is reconsidered based on the position of the nearest boxes. The steps to measure the CA is presented in Figure 7.

Get 4 corners and center location for each vertebrae

\section{Find apex} Find the most tilted vertebrae above $(a a)$ and below apex $(b a)$
Draw lines following slope $a a$ and $b a$
Calculate the angle at the intersection

Figure 7. Steps to measure the CA.

Curvature quantification, the depth of the curve at the found position of the corner box, was obtained (Figure 8). For each of the two vertebrae, the distances between the bottom-left point of the upper box and the top-left of the lower box (L1-L11), and the bottom-right point of the upper box and the top-right of the lower box (R1-R11) were calculated. The apex of the spine curvature is found as the deepest part of the curve. For each box above the apex, the slope of each vertebrae is measured based on the position between top-left and top-right to detect the most-tilted vertebrae above the apex. For each box below the apex, the slope of each vertebra is measured based on the position between bottom-left and bottom-right to detect most-tilted vertebra below the apex. The location of the superior end vertebra and inferior end vertebra is identified as the most tilted vertebra above apex (aa) and below apex $(b a)$, respectively. CA measured as the angle of the intersection between two lines from $a a$ to $b a$. Figure 9 shows an example of a measurement performed by the ACAMM.

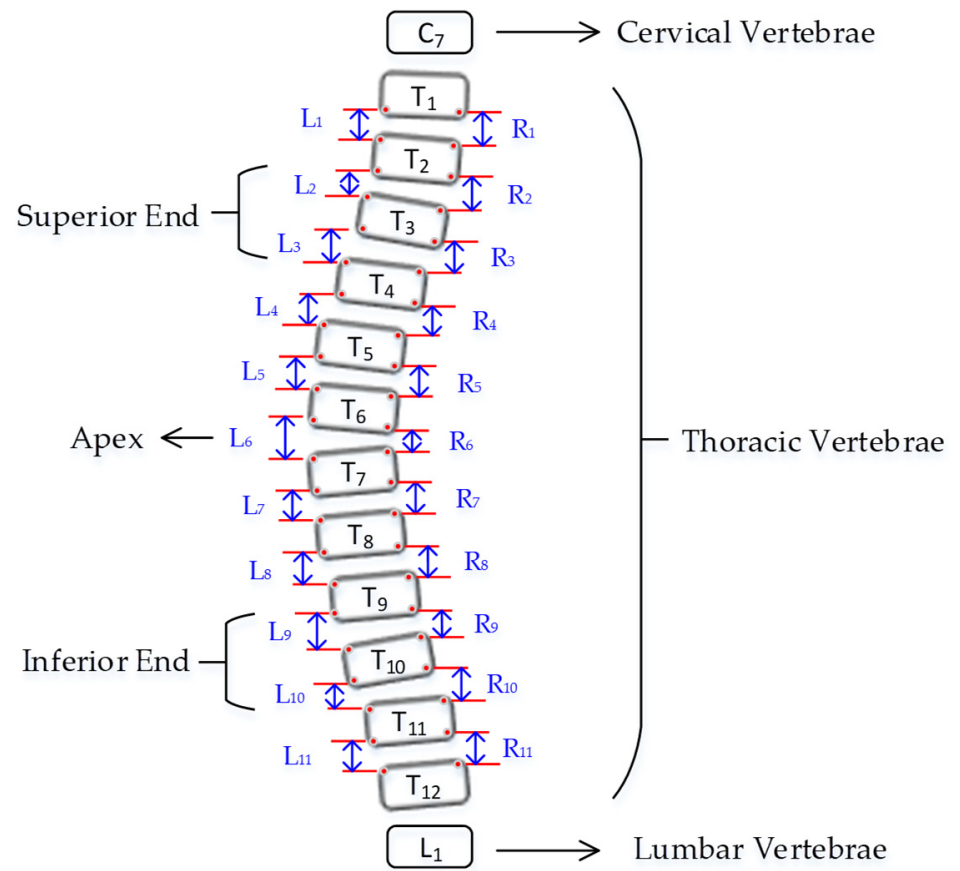

Figure 8. Vertebrae anatomy for the illustration of finding apex, superior end, and inferior end- vertebrae. 


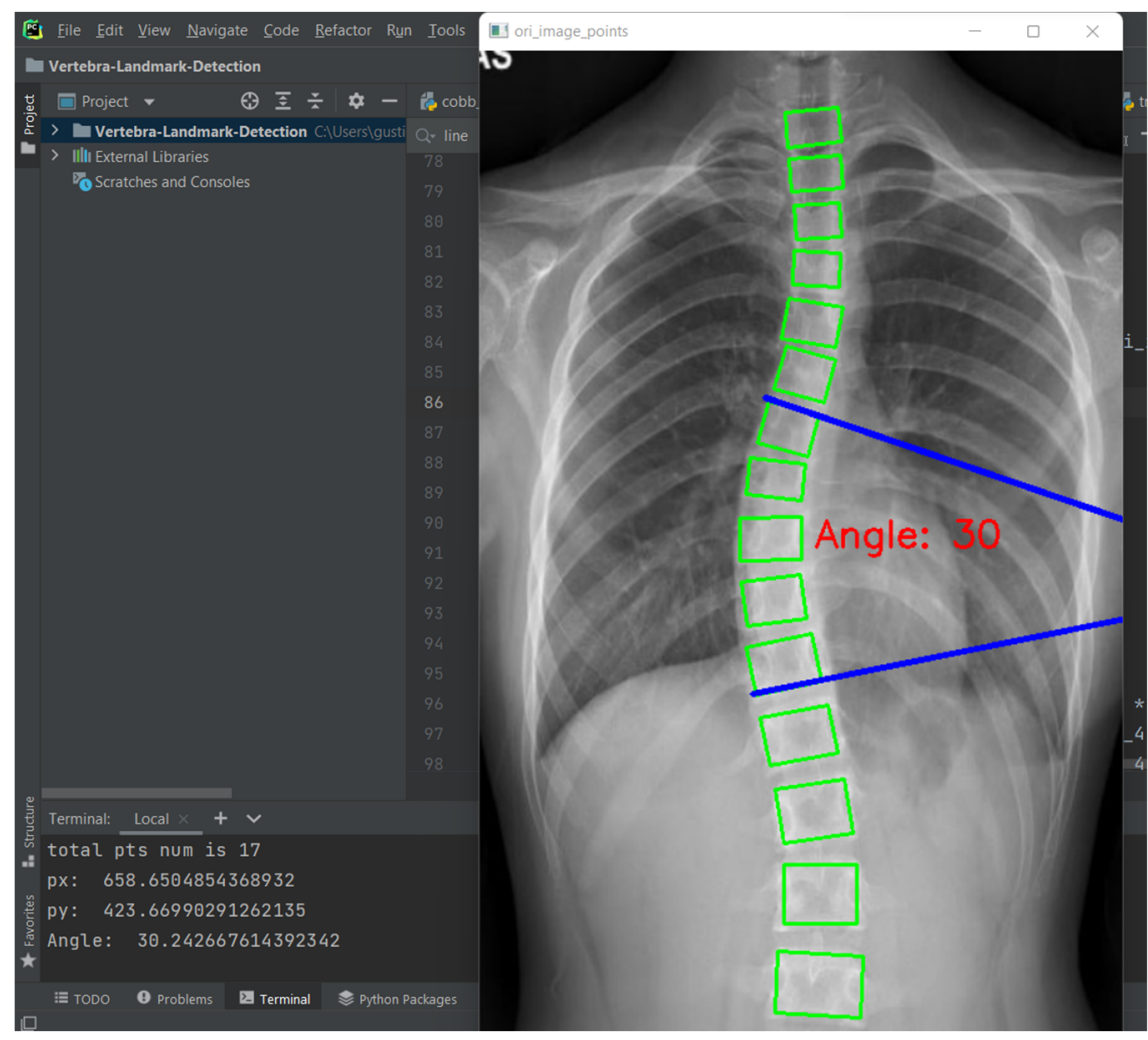

Figure 9. Automated vertebrae detection and CA measurement.

\subsection{Statistical Analysis}

All statistical analyses were performed with SPSS version 20 (IBM Corporation, Armonk, New York, United States of America). The chi-squared test and the Mann-Whitney $U$ test were performed for nominal and non-normally distributed variables, respectively. Using Observer 1 as the reference, median percentage accuracy (Interquartile Range (IQR)), median CA measurement differences (IQR), and proportion of CA measurements within $\pm 5^{\circ}$ comparing the ACAMM to Observer 2 was calculated. The percentage accuracy was calculated based on the following formula:

$$
\text { Percentage accuracy }(\%)=100-100\left(\left|\frac{\bar{C}-\dot{C}}{\bar{C}}\right|\right)
$$

where $\bar{C}$ is the Observer 1 CA measurement and $C$ is ACAMM (or Observer 2) CA measurement.

The reliability of the ACAMM using our proposed CNN was assessed by Intraclass Correlation Coefficient (ICC) and Pearson Correlation Coefficient (PCC). Generally, the ICC reliability values are rated as poor $(<0.50)$, fair $(0.50$ to 0.75$)$, good $(>0.75$ to 0.90$)$, or excellent $(>0.90)$. The significance level for the study was set at $p<0.05$.

\section{Results}

\subsection{Vertebrae Detection Results}

The datasets were trained on the RTX2060 GPU with Intel Core-i7 processor. The proposed architecture using CNN accurately detected the location of each of the 17 vertebrae in the spine X-ray. In addition to this, the bounding box was evaluated to be sufficient in its accordance with the vertebra positions. Its performance was accurate to provide the information needed to detect the superior and inferior end vertebrae, enabling the CA to be evaluated correctly.

The detection results also showed that the proposed architecture could be used to identify the vertebrae in X-ray images of different contrast and lighting conditions (see Appendix A, Figure A1). Our test on several images with poor contrast and lighting 
conditions yielded good results. Importantly, CA measurements and curve classification were able to be accurately accomplished even when the detection process failed to identify one or two vertebrae due to our curve fitting and quantification method. Previous studies using CNN $[14,16]$ focused on vertebrae detection and measurement of CA under certain conditions. The method we proposed was able to measure CA from normal to severely scoliotic spine (up to $79^{\circ}$ ). This is a key part of the algorithm as X-ray images may come in different contrast and lighting qualities in the clinical setting, depending on the severity of the curve as well as the patient's body habitus.

\subsection{Evaluation of Automated CA Measurement Results and Ground Truth}

The results of the ACAMM were compared with the results measured by two Neurosurgeons (Observer 1 specializes in scoliosis; Observer 2 does not) as shown in Tables 1-4. Using Observer 1 as the reference, the ACAMM showed better median accuracy $(93.6 \%$ [89.7\% to $97.7 \%$ ] vs. $85.9 \%$ [ $78.3 \%$ to $95.5 \%$ ],$p<0.001$ ), smaller median CA measurement differences $\left(0^{\circ}\left[-3.0^{\circ}\right.\right.$ to $\left.2.0^{\circ}\right]$ vs. $-3.0^{\circ}\left[-8.0^{\circ}\right.$ to $\left.\left.0^{\circ}\right], p<0.001\right)$ and higher percentage of CA measurements within $\pm 5^{\circ}(98.6 \%$ [69/70] vs. $54.3 \%$ [38/70], $p=0.001)$, compared to Observer 2 (Table 5).

Table 1. X-ray images evaluation for Cobb angle $<10^{\circ}$.

\begin{tabular}{|c|c|c|c|c|c|c|c|c|c|}
\hline Image & $\begin{array}{l}\text { Observer } 1 \\
\text { Reference } \\
\text { CA Mea- } \\
\text { surement } \\
\left(^{\circ}\right)\end{array}$ & $\begin{array}{c}\text { Observer } 2 \\
\text { CA Mea- } \\
\text { surement } \\
\left({ }^{\circ}\right)\end{array}$ & $\begin{array}{c}\text { Observer } \\
\text { 2-Observer } 1 \\
\text { CA Difference } \\
\left({ }^{\circ}\right)\end{array}$ & $\begin{array}{c}\text { CA } \\
\text { Difference } \\
\text { within } \pm 5^{\circ}\end{array}$ & $\begin{array}{c}\text { Observer } 2 \\
\text { Accuracy } \\
(\%)\end{array}$ & $\begin{array}{c}\text { ACAMM } \\
\left({ }^{\circ}\right)\end{array}$ & $\begin{array}{c}\text { ACAMM- } \\
\text { Observer } 1 \text { CA } \\
\text { Difference }\left(^{\circ}\right)\end{array}$ & $\begin{array}{c}\text { CA } \\
\text { Difference } \\
\text { within } \pm 5^{\circ}\end{array}$ & $\begin{array}{c}\text { ACAMM } \\
\text { Accuracy } \\
(\%)\end{array}$ \\
\hline 1 & 9 & 9 & 0 & Yes & 100.0 & 11 & +2 & Yes & 77.8 \\
\hline 2 & 8 & 6 & -2 & Yes & 75.0 & 8 & 0 & Yes & 100.0 \\
\hline 3 & 6 & 2 & -4 & Yes & 33.3 & 4 & -2 & Yes & 66.7 \\
\hline 4 & 5 & 3 & -2 & Yes & 100.0 & 6 & +1 & Yes & 40.0 \\
\hline 5 & 9 & 6 & -3 & Yes & 66.7 & 10 & +1 & Yes & 88.9 \\
\hline 6 & 5 & 4 & -1 & Yes & 80.0 & 7 & +2 & Yes & 60.0 \\
\hline
\end{tabular}

Note: Cobb Angle (CA); Automated Cobb Angle Measurement Method (ACAMM).

Table 2. X-ray images evaluation for Cobb angle $10^{\circ}$ to $25^{\circ}$.

\begin{tabular}{|c|c|c|c|c|c|c|c|c|c|}
\hline Image & $\begin{array}{c}\text { Observer } 1 \\
\text { Reference } \\
\text { CA Mea- } \\
\text { surement } \\
\left(^{\circ}\right)\end{array}$ & $\begin{array}{c}\text { Observer } 2 \\
\text { CA Mea- } \\
\text { surement } \\
\left({ }^{\circ}\right)\end{array}$ & $\begin{array}{c}\text { Observer } \\
\text { 2-Observer } 1 \\
\text { CA Difference } \\
\left.{ }^{\circ}\right)\end{array}$ & $\begin{array}{c}\text { CA } \\
\text { Difference } \\
\text { within } \pm 5^{\circ}\end{array}$ & $\begin{array}{c}\text { Observer } 2 \\
\text { Accuracy } \\
(\%)\end{array}$ & $\begin{array}{c}\text { ACAMM } \\
\left({ }^{\circ}\right)\end{array}$ & $\begin{array}{c}\text { ACAMM- } \\
\text { Observer } 1 \text { CA } \\
\text { Difference }\left(^{\circ}\right)\end{array}$ & $\begin{array}{c}\text { CA } \\
\text { Difference } \\
\text { within } \pm 5^{\circ}\end{array}$ & $\begin{array}{c}\text { ACAMM } \\
\text { Accuracy } \\
(\%)\end{array}$ \\
\hline 7 & 13 & 8 & -5 & Yes & 61.5 & 9 & -4 & Yes & 69.2 \\
\hline 8 & 10 & 10 & 0 & Yes & 100.0 & 7 & -3 & Yes & 70.0 \\
\hline 9 & 10 & 8 & -2 & Yes & 80.0 & 12 & +2 & Yes & 80.0 \\
\hline 10 & 10 & 9 & -1 & Yes & 90.0 & 9 & -1 & Yes & 90.0 \\
\hline 11 & 13 & 12 & -1 & Yes & 92.3 & 16 & +3 & Yes & 76.9 \\
\hline 12 & 22 & 21 & -1 & Yes & 95.5 & 19 & -3 & Yes & 86.4 \\
\hline 13 & 21 & 19 & -2 & No & 90.5 & 19 & -2 & Yes & 90.5 \\
\hline 14 & 23 & 23 & 0 & Yes & 100.0 & 23 & 0 & Yes & 100.0 \\
\hline 15 & 23 & 21 & -2 & Yes & 91.3 & 23 & 0 & Yes & 100.0 \\
\hline 16 & 23 & 29 & +6 & No & 73.9 & 27 & +4 & Yes & 82.6 \\
\hline 17 & 22 & 20 & -2 & Yes & 90.9 & 18 & -4 & Yes & 81.8 \\
\hline 18 & 22 & 25 & +3 & Yes & 86.4 & 17 & -5 & Yes & 77.3 \\
\hline 19 & 14 & 14 & 0 & Yes & 100.0 & 13 & -1 & Yes & 92.9 \\
\hline 20 & 19 & 16 & -3 & Yes & 84.2 & 19 & 0 & Yes & 100.0 \\
\hline 21 & 16 & 10 & -6 & No & 62.5 & 17 & +1 & Yes & 93.8 \\
\hline 22 & 24 & 19 & -5 & Yes & 79.2 & 22 & -2 & Yes & 91.7 \\
\hline 23 & 21 & 21 & 0 & Yes & 100.0 & 22 & +1 & Yes & 95.2 \\
\hline 24 & 19 & 19 & 0 & Yes & 100.0 & 19 & 0 & Yes & 100.0 \\
\hline 25 & 20 & 21 & +1 & Yes & 95.0 & 19 & -1 & Yes & 95.0 \\
\hline
\end{tabular}

Note: Cobb Angle (CA); Automated Cobb Angle Measurement Method (ACAMM). 
Table 3. X-ray images evaluation for Cobb angle $>25^{\circ}$ to $40^{\circ}$.

\begin{tabular}{|c|c|c|c|c|c|c|c|c|c|}
\hline Image & $\begin{array}{l}\text { Observer } 1 \\
\text { Reference } \\
\text { CA Mea- } \\
\text { surement } \\
\left({ }^{\circ}\right)\end{array}$ & $\begin{array}{c}\text { Observer } 2 \\
\text { CA Mea- } \\
\text { surement } \\
\left({ }^{\circ}\right)\end{array}$ & $\begin{array}{c}\text { Observer } \\
\text { 2-Observer } 1 \\
\text { CA Difference } \\
\left(^{\circ}\right)\end{array}$ & $\begin{array}{c}\text { CA } \\
\text { Difference } \\
\text { within } \pm 5^{\circ}\end{array}$ & $\begin{array}{c}\text { Observer } 2 \\
\text { Accuracy } \\
(\%)\end{array}$ & $\begin{array}{c}\text { ACAMM } \\
\left({ }^{\circ}\right)\end{array}$ & $\begin{array}{c}\text { ACAMM- } \\
\text { Observer } 1 \text { CA } \\
\text { Difference }\left({ }^{\circ}\right)\end{array}$ & $\begin{array}{c}\text { CA } \\
\text { Difference } \\
\text { within } \pm 5^{\circ}\end{array}$ & $\begin{array}{c}\text { ACAMM } \\
\text { Accuracy } \\
(\%)\end{array}$ \\
\hline 26 & 38 & 30 & -8 & No & 78.9 & 40 & +2 & Yes & 94.7 \\
\hline 27 & 30 & 31 & +1 & Yes & 96.7 & 34 & +4 & Yes & 86.7 \\
\hline 28 & 27 & 26 & -1 & Yes & 96.3 & 23 & -4 & Yes & 85.2 \\
\hline 29 & 40 & 33 & -7 & No & 82.5 & 42 & +2 & Yes & 95.0 \\
\hline 30 & 27 & 28 & +1 & Yes & 96.3 & 29 & +2 & Yes & 92.6 \\
\hline 31 & 29 & 25 & -4 & Yes & 86.2 & 33 & +4 & Yes & 86.2 \\
\hline 32 & 34 & 26 & -8 & No & 76.5 & 32 & -2 & Yes & 94.1 \\
\hline 33 & 36 & 30 & -6 & No & 83.3 & 35 & -1 & Yes & 97.2 \\
\hline 34 & 35 & 42 & +7 & No & 80.0 & 32 & -3 & Yes & 91.4 \\
\hline 35 & 34 & 40 & +6 & No & 82.4 & 36 & +2 & Yes & 94.1 \\
\hline 36 & 31 & 31 & 0 & Yes & 100.0 & 28 & -3 & Yes & 90.3 \\
\hline 37 & 31 & 30 & -1 & Yes & 96.8 & 28 & -3 & Yes & 90.3 \\
\hline 38 & 36 & 47 & +11 & No & 69.4 & 32 & -4 & Yes & 88.9 \\
\hline 39 & 35 & 39 & +4 & Yes & 88.6 & 34 & -1 & Yes & 97.1 \\
\hline 40 & 29 & 27 & -2 & Yes & 93.1 & 28 & -1 & Yes & 96.6 \\
\hline
\end{tabular}

Note: Cobb Angle (CA); Automated Cobb Angle Measurement Method (ACAMM).

Table 4. X-ray images evaluation for Cobb angle $>40^{\circ}$.

\begin{tabular}{|c|c|c|c|c|c|c|c|c|c|}
\hline Image & $\begin{array}{c}\text { Observer } 1 \\
\text { Reference } \\
\text { CA Mea- } \\
\text { surement } \\
\left.\quad{ }^{\circ}\right)\end{array}$ & $\begin{array}{c}\text { Observer } 2 \\
\text { CA Mea- } \\
\text { surement } \\
\left({ }^{\circ}\right)\end{array}$ & $\begin{array}{c}\text { Observer } \\
\text { 2-Observer } 1 \\
\text { CA Difference } \\
\left(^{\circ}\right)\end{array}$ & $\begin{array}{c}\text { CA } \\
\text { Difference } \\
\text { within } \pm 5^{\circ}\end{array}$ & $\begin{array}{c}\text { Observer } 2 \\
\text { Accuracy } \\
(\%)\end{array}$ & $\begin{array}{c}\text { ACAMM } \\
\left({ }^{\circ}\right)\end{array}$ & $\begin{array}{c}\text { ACAMM- } \\
\text { Observer } 1 \text { CA } \\
\text { Difference }\left(^{\circ}\right)\end{array}$ & $\begin{array}{c}\text { CA } \\
\text { Difference } \\
\text { within } \pm 5^{\circ}\end{array}$ & $\begin{array}{c}\text { ACAMM } \\
\text { Accuracy } \\
(\%)\end{array}$ \\
\hline 41 & 47 & 36 & -11 & No & 76.6 & 48 & 1 & Yes & 97.9 \\
\hline 42 & 42 & 37 & -5 & Yes & 88.1 & 45 & 3 & Yes & 92.9 \\
\hline 43 & 46 & 35 & -11 & No & 76.1 & 50 & 4 & Yes & 91.3 \\
\hline 44 & 46 & 48 & 2 & Yes & 95.7 & 50 & 4 & Yes & 91.3 \\
\hline 45 & 41 & 29 & -12 & No & 70.7 & 38 & -3 & Yes & 92.7 \\
\hline 46 & 50 & 33 & -17 & No & 66.0 & 46 & -4 & Yes & 92.0 \\
\hline 47 & 41 & 33 & -8 & No & 80.5 & 45 & 4 & Yes & 90.2 \\
\hline 48 & 52 & 35 & -17 & No & 67.3 & 52 & 0 & Yes & 100.0 \\
\hline 49 & 42 & 33 & -9 & No & 78.6 & 44 & 2 & Yes & 95.2 \\
\hline 50 & 51 & 42 & -9 & No & 82.4 & 49 & -2 & Yes & 96.1 \\
\hline 51 & 43 & 37 & -6 & No & 86.0 & 42 & -1 & Yes & 97.7 \\
\hline 52 & 53 & 34 & -19 & No & 64.2 & 49 & -4 & Yes & 92.5 \\
\hline 53 & 51 & 34 & -17 & No & 66.7 & 52 & 1 & Yes & 98.0 \\
\hline 54 & 51 & 41 & -10 & No & 80.4 & 51 & 0 & Yes & 100.0 \\
\hline 55 & 45 & 41 & -4 & Yes & 91.1 & 44 & -1 & Yes & 97.8 \\
\hline 56 & 58 & 56 & -2 & Yes & 96.6 & 61 & 3 & Yes & 94.8 \\
\hline 57 & 58 & 64 & 6 & No & 89.7 & 54 & -4 & Yes & 93.1 \\
\hline 58 & 70 & 56 & -14 & No & 80.0 & 67 & -3 & Yes & 95.7 \\
\hline 59 & 68 & 65 & -3 & Yes & 95.6 & 65 & -3 & Yes & 95.6 \\
\hline 60 & 59 & 51 & -8 & No & 86.4 & 58 & -1 & Yes & 98.3 \\
\hline 61 & 62 & 48 & -14 & No & 77.4 & 58 & -4 & Yes & 93.5 \\
\hline 62 & 56 & 42 & -14 & No & 75.0 & 55 & -1 & Yes & 98.2 \\
\hline 63 & 56 & 56 & 0 & Yes & 100.0 & 57 & 1 & Yes & 98.2 \\
\hline 64 & 79 & 73 & -6 & No & 92.4 & 79 & 0 & Yes & 100.0 \\
\hline 65 & 56 & 45 & -11 & No & 80.4 & 57 & 1 & Yes & 98.2 \\
\hline 66 & 65 & 63 & -2 & Yes & 96.9 & 66 & 1 & Yes & 98.5 \\
\hline 67 & 62 & 50 & -12 & No & 80.6 & 64 & 2 & Yes & 96.8 \\
\hline 68 & 56 & 48 & -8 & No & 85.7 & 58 & 2 & Yes & 96.4 \\
\hline 69 & 60 & 54 & -6 & No & 90.0 & 54 & -6 & No & 90.0 \\
\hline 70 & 74 & 63 & -11 & No & 85.1 & 75 & 1 & Yes & 98.6 \\
\hline
\end{tabular}


Table 5. Comparison between automated Cobb angle measurement method and Observer 2.

\begin{tabular}{|c|c|c|c|}
\hline & ACAMM vs. Observer 1 & Observer 2 vs. Observer 1 & $p$ \\
\hline \multicolumn{4}{|l|}{ Overall } \\
\hline Median accuracy, \% (IQR) & 93.6 (89.7 to 97.7$)$ & 85.9 (78.3 to 95.5$)$ & $<0.001$ \\
\hline Median CA difference, ${ }^{\circ}$ (IQR) & $0(-3.0$ to 2.0$)$ & $-3.0(-8.0$ to 0$)$ & $<0.001$ \\
\hline CA difference within $\pm 5^{\circ}, \mathrm{n}(\%)$ & $69 / 70(98.6)$ & $38 / 70(54.3)$ & $<0.001$ \\
\hline \multicolumn{4}{|l|}{$\mathrm{CA}<10^{\circ}$} \\
\hline Median accuracy, \% (IQR) & 72.3 (55.0 to 91.7 ) & 77.5 (58.4 to 100$)$ & 0.686 \\
\hline Median CA difference, ${ }^{\circ}$ (IQR) & $1.0(-0.5$ to 2.0$)$ & $-2.0(-3.3$ to -0.8$)$ & 0.019 \\
\hline CA difference within $\pm 5^{\circ}, \mathrm{n}(\%)$ & $6 / 6(100)$ & $6 / 6(100)$ & N/A \\
\hline \multicolumn{4}{|l|}{ CA $10^{\circ}$ to $25^{\circ}$} \\
\hline Median accuracy, \% (IQR) & 90.5 (80.0 to 95.2$)$ & $90.9(80.0$ to 100$)$ & 0.837 \\
\hline Median CA difference, ${ }^{\circ}$ (IQR) & $-1.0(-3.0$ to 1.0$)$ & $-1.0(-2.0$ to 0$)$ & 0.669 \\
\hline CA difference within $\pm 5^{\circ}, \mathrm{n}(\%)$ & $19 / 19(100.0)$ & $17 / 19(89.5)$ & 0.146 \\
\hline \multicolumn{4}{|l|}{$\mathrm{CA}>25^{\circ}$ to $40^{\circ}$} \\
\hline Median accuracy, \% (IQR) & $92.6(88.9$ to 95.0$)$ & 86.2 (80.0 to 96.3 ) & 0.146 \\
\hline Median CA difference, ${ }^{\circ}$ (IQR) & $-1.0(-3.0$ to 2.0$)$ & $-1.0(-6.0$ to 4.0$)$ & 0.835 \\
\hline CA difference within $\pm 5^{\circ}, \mathrm{n}(\%)$ & $15 / 15(100)$ & $8 / 15(53.3)$ & 0.003 \\
\hline \multicolumn{4}{|l|}{$\mathrm{CA}>40^{\circ}$} \\
\hline Median accuracy, \% (IQR) & 96.3 (92.9 to 98.2$)$ & 81.5 (76.5 to 90.3$)$ & $<0.001$ \\
\hline Median CA difference, ${ }^{\circ}$ (IQR) & $0(-3.0$ to 2.0$)$ & $-9(-12.5$ to -4.8$)$ & $<0.001$ \\
\hline CA difference within $\pm 5^{\circ}, \mathrm{n}(\%)$ & $29 / 30(96.7)$ & $7 / 30(23.3)$ & $<0.001$ \\
\hline
\end{tabular}

Note: The chi-square test and the Mann-Whitney U test were performed for nominal and non-normally distributed variables, respectively. Cobb Angle (CA); Automated Cobb Angle Measurement Method (ACAMM); Interquartile Range (IQR).

Overall, the ACAMM was highly matched to the CA assessment performed by the two observers (Table 6). ICC for the ACAMM compared to Observer 1 and Observer 2 was 0.995 and 0.954 , respectively. The PCC also showed high correlation between the ACAMM and Observer $1(0.991, p<0.001)$ and Observer $2(0.931, p<0.001)$.

Table 6. The reliability of the proposed ACAMM.

\begin{tabular}{ccc}
\hline & ICC & PCC \\
\hline Observer 1-Observer 2 & 0.957 & $0.948(p<0.001)$ \\
Observer 1-ACAMM & 0.995 & $0.991(p<0.001)$ \\
Observer 2-ACAMM & 0.954 & $0.939(p<0.001)$ \\
\hline
\end{tabular}

Note: Automated Cobb Angle Measurement Method (ACAMM); Intraclass Correlation Coefficient (ICC); Pearson Correlation Coefficient (PCC).

\section{Discussions}

Our proposed method of automatic assessment of CA on spine X-ray images used ResNet-152 as a backbone to improve the performance accuracy. We used feature maps classification with a sigmoid function as network depth has previously been shown to be beneficial in classification accuracy. However, its performance can become saturated with a resultant rapid decrease in performance as the network gains greater depth. This issue can be corrected by the ResNet framework, where a shortcut connection is added for every three convolution layers across the deep network. These shortcut connections performed identity mapping without additional parameters, which can increase computational complexity. This simplification of network optimization during the training process enabled ResNet to achieve a higher accuracy from deeper networks when performing image segmentation tasks. Curve fitting and quantification were used to handle errors in vertebrae detection so that accurate CA measurements could still be obtained.

Reproducibility remains a common problem in CA measurements due to the high degree of intra-observer and inter-observer variabilities. An objective, reliable method to determine CA is crucial, as this measurement is used to determine and guide clinical decisions regarding diagnosis, curve progression, and management, including surgical options. Our ACAMM showed good CA measurement accuracies (93.6\%) when assessed against a neurosurgeon with expertise in scoliosis. Importantly, all except for one (98.6\%) of the automated measurements were within $\pm 5^{\circ}$ in CA measurements of the expert 
neurosurgeon. Generally, this variation is within the accepted threshold when measuring CA in the clinical setting [5,8]. This was in contrast to the second observer, where only $54.3 \%$ of the CA measurements were within $\pm 5^{\circ}$. Furthermore, the reliability of our proposed method to measure CA was excellent (ICC > 0.95, PCC > 0.93). The results, which are highly matched with the assessment performed by the two neurosurgeons, indicate that this CNN method has a high potential for its use in the real-world setting.

There are limitations to this study. The results shown were performed in a non-clinical setting. Therefore, further tests of reliability and accuracy in the clinical setting with realtime comparisons with the clinicians' CA measurement, including an increase in the testing samples and observers, is warranted. Secondly, the current method is only able to measure a single major curvature in the spine and cannot detect other minor curves in the same $\mathrm{X}$-rays, which may be clinically relevant. Future work to enable the ability of the algorithm to detect all the curves in the scoliotic spine X-ray will be explored.

\section{Conclusions}

We developed a pre-processing method and a deep learning architecture using a convolutional neural network for spine segmentation and vertebrae detection to automatically measure Cobb angle in adolescent idiopathic scoliosis. The vertebrae detection network uses ResNet-152 as the backbone, feature maps classification, and corner offset compensation to improve the performance accuracy. The proposed method demonstrates good measurement accuracies when compared against an expert in scoliosis and has an excellent reliability rating, indicating it is a promising method for automatic measurement of Cobb angle in a real-world setting.

Author Contributions: Conceptualization, W.C. and A.T.; methodology, W.C., W.R., J.M. and A.T.; software, W.C. and W.R.; validation, W.C., W.R., J.M. and A.T.; formal analysis, W.C., W.R. and A.T.; investigation, W.C., W.R., J.M. and A.T.; resources, J.M. and A.T.; data curation, W.R. and A.T.; writing-original draft preparation, W.C., W.R. and A.T.; writing-review and editing, W.C., W.R., J.M. and A.T.; visualization, WC., W.R. and A.T.; supervision, W.C., J.M. and A.T.; project administration, W.C. and A.T.; funding acquisition, W.C. and A.T. All authors have read and agreed to the published version of the manuscript.

Funding: This project was supported by The AO Spine National Research Grant 2020 [AOSEA(R)202005]. The APC was partially funded by Wahyu Caesarendra.

Institutional Review Board Statement: The study was conducted according to the guidelines of the Declaration of Helsinki and approved on 24 October 2020 by the Medical and Health Research and Ethics Committee, Ministry of Health, Brunei Darussalam (MHREC/MOH/2020/15).

Informed Consent Statement: Patient consent was waived due to minimal risk exposure as this study did not involve patients and was a non-interventional study.

Conflicts of Interest: The authors declare no conflict of interest. 
Appendix A. CNN Cobb Angle (CA) Measurement of X-ray Images

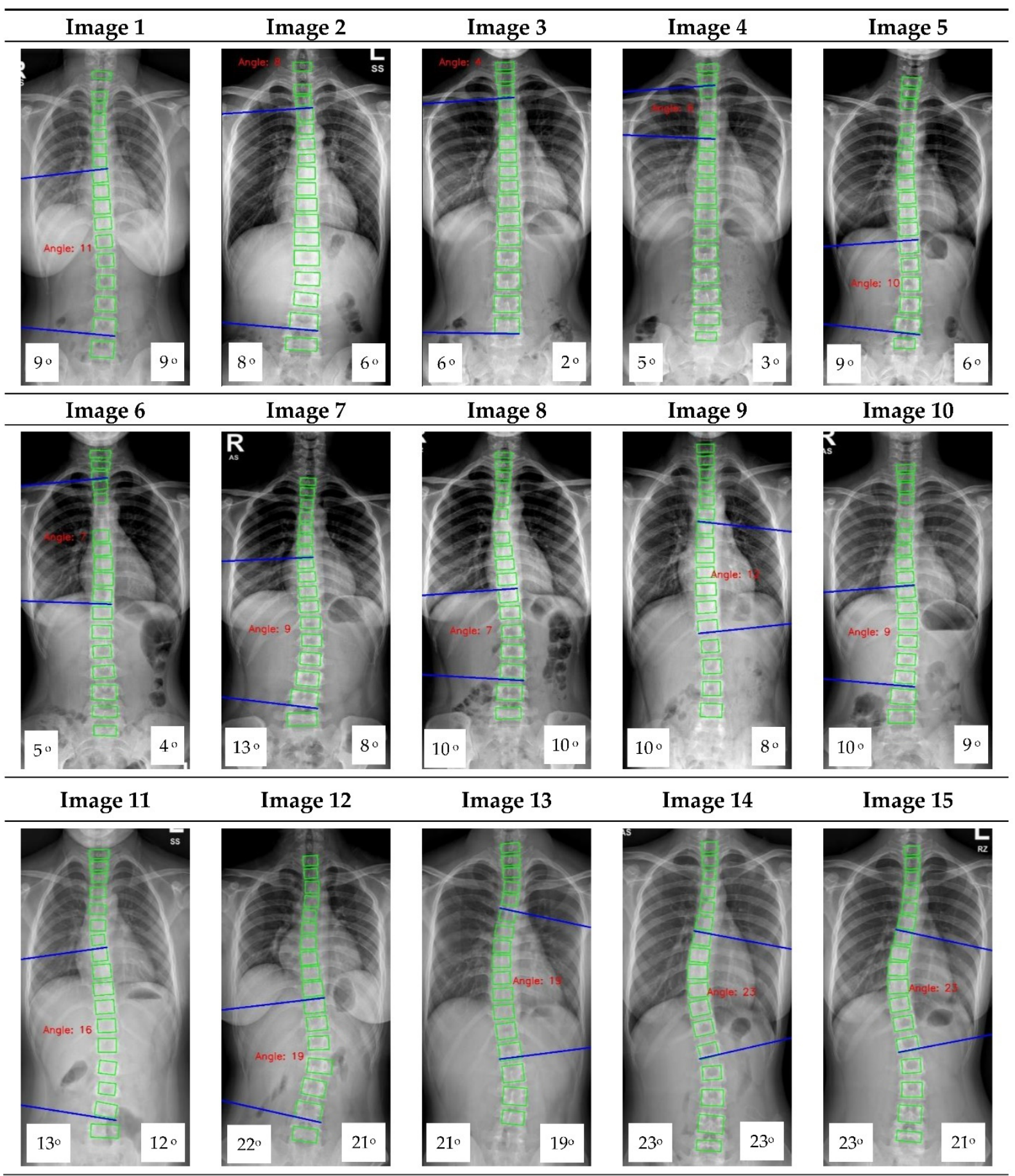

Figure A1. Cont. 

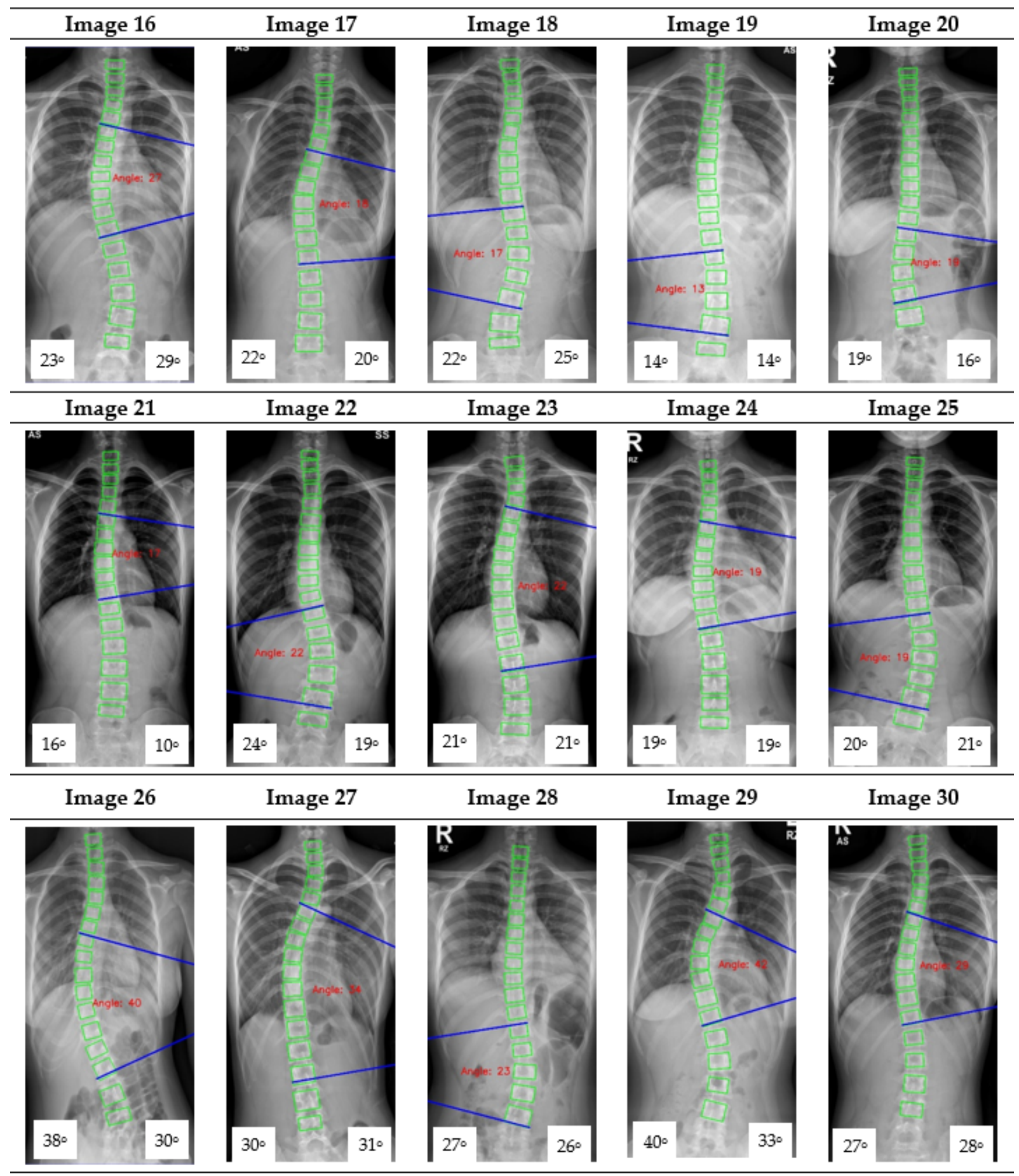

Figure A1. Cont. 


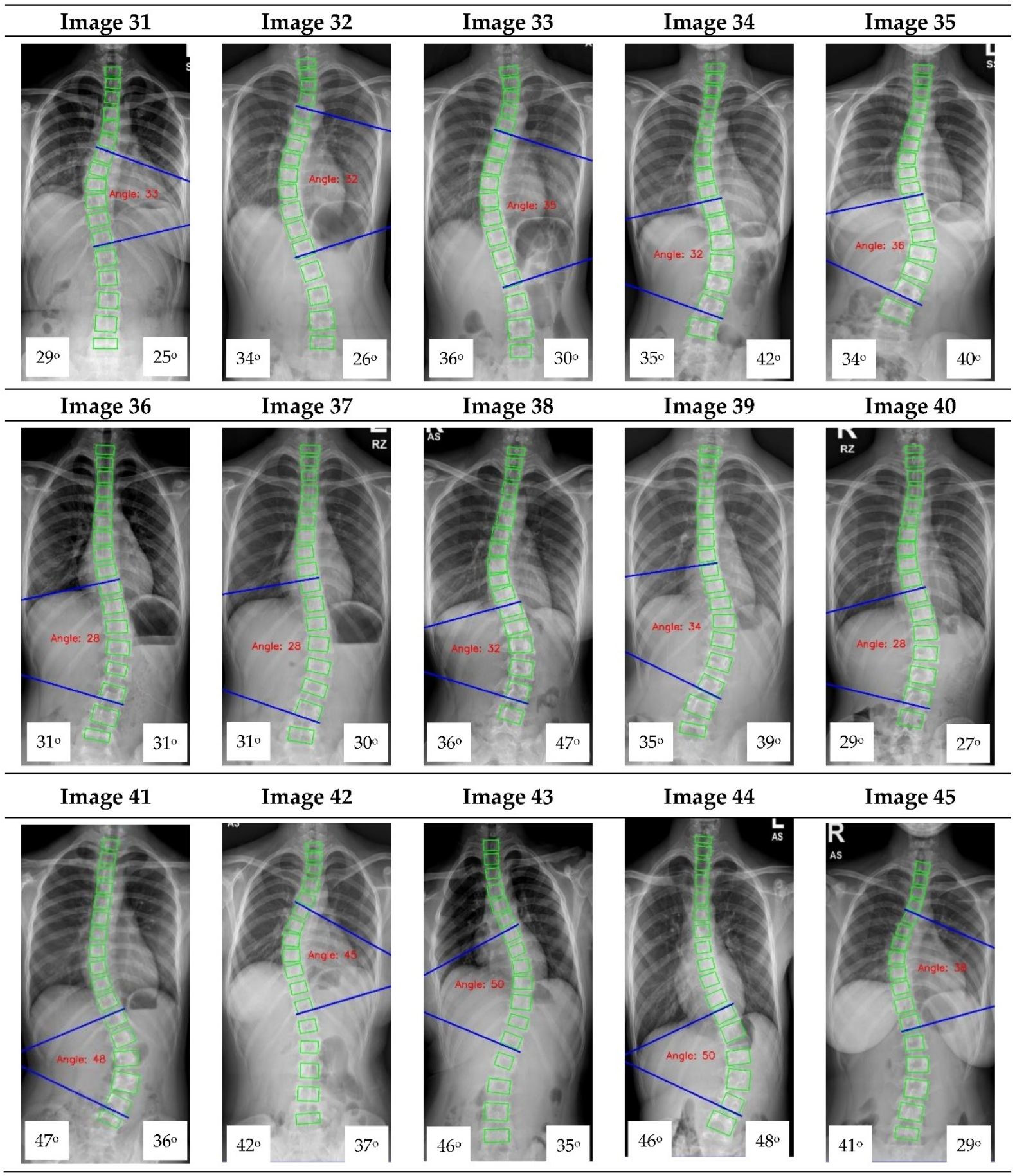

Figure A1. Cont. 

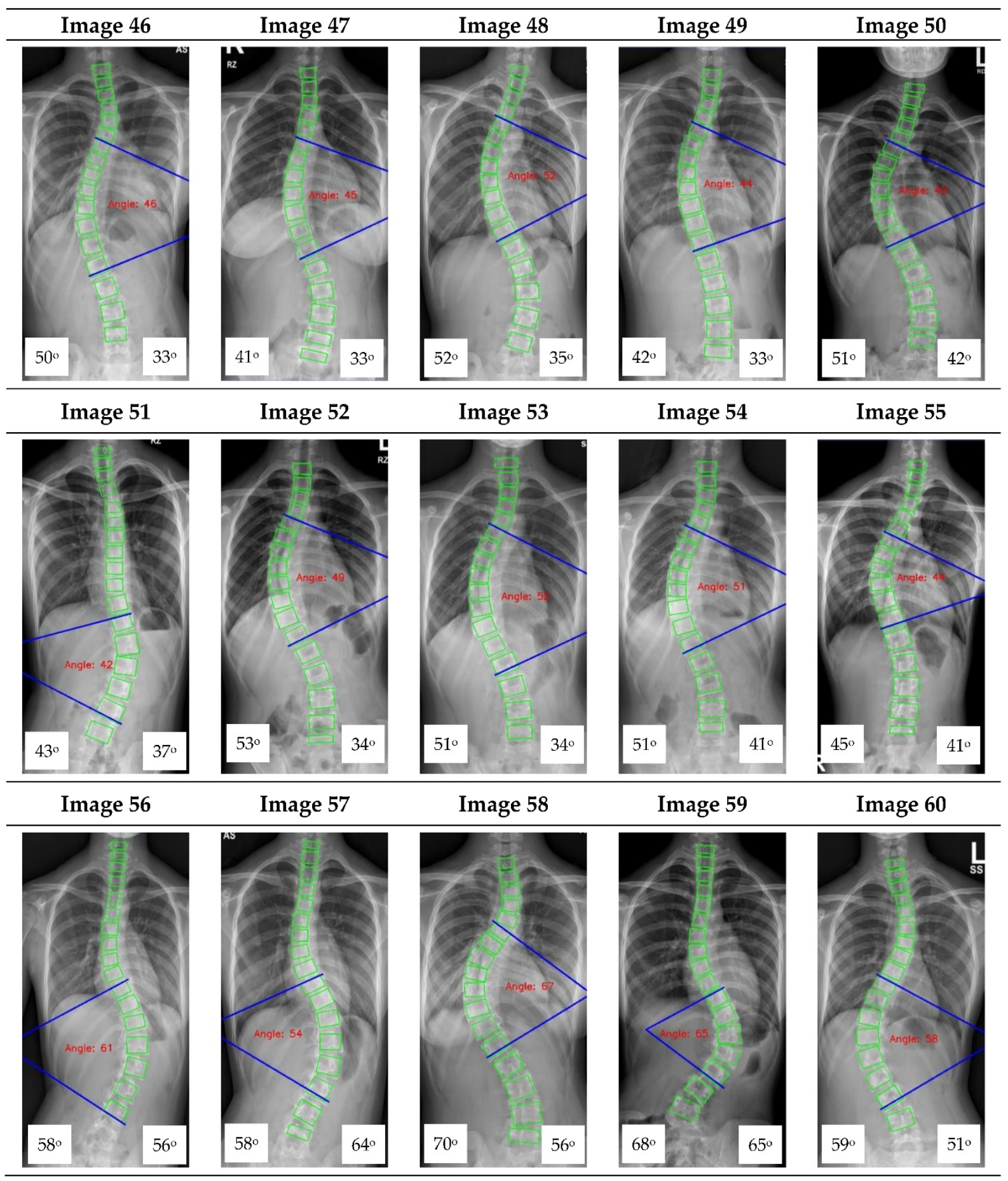

Figure A1. Cont. 


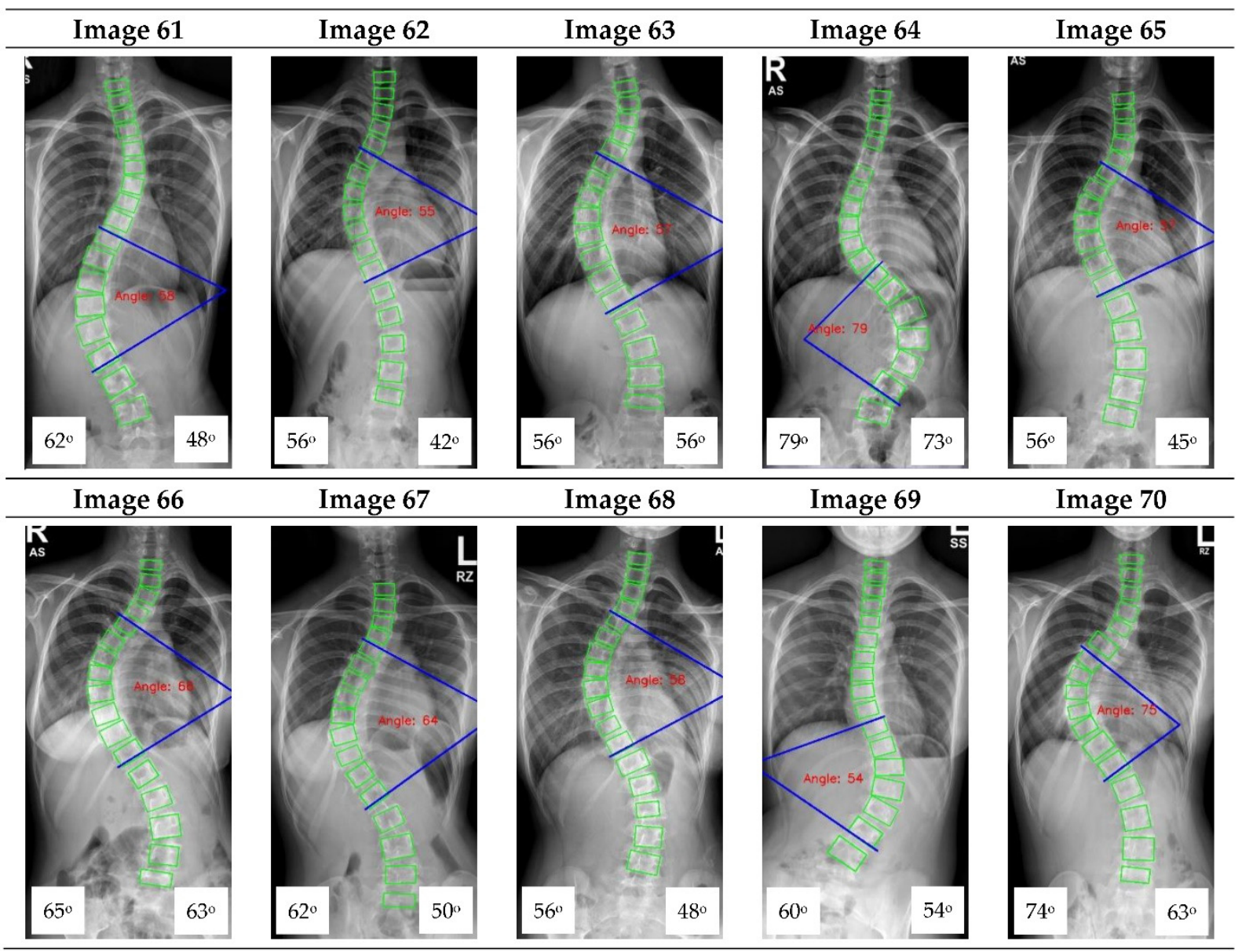

Figure A1. The red font inside the X-ray image is a CNN CA measurement. Observer 1 and 2 evaluation is presented on the bottom left and right, respectively.

\section{References}

1. Konieczny, M.R.; Senyurt, H.; Krauspe, R. Epidemiology of adolescent idiopathic scoliosis. J. Child. Orthop. 2013, 7, 3-9. [CrossRef] [PubMed]

2. Altaf, F.; Gibson, A.; Dannawi, Z.; Noordeen, H. Adolescent idiopathic scoliosis. BMJ 2013, 346. [CrossRef]

3. Dunn, J.; Henrikson, N.B.; Morrison, C.C.; Blasi, P.R.; Nguyen, M.; Lin, J.S. Screening for adolescent idiopathic scoliosis: Evidence report and systematic review for the US preventive services task force. JAMA 2018, 319, 173-187. [CrossRef]

4. Cobb, J. Outline for the study of scoliosis. Instr. Course Lect. AAOS 1948, 5, 261-275.

5. Carman, D.L.; Browne, R.H.; Birch, J.G. Measurement of scoliosis and kyphosis radiographs. Intraobserver and interobserver variation. J. Bone Jt. Surg. Am. 1990, 72, 328-333. [CrossRef] [PubMed]

6. Cheung, J.; Wever, D.J.; Veldhuizen, A.G.; Klein, J.P.; Verdonck, B.; Nijlunsing, R.; Cool, J.C.; Horn, J.R.V. The reliability of quantitative analysis on digital images of the scoliotic spine. Eur. Spine J. 2002, 11, 535-542. [CrossRef]

7. Shea, K.G.; Stevens, P.M.; Nelson, M.; Smith, J.T.; Masters, K.S.; Yandow, S. A comparison of manual versus computer-assisted radiographic measurement: Intraobserver measurement variability for Cobb angles. Spine 1998, 23, 551-555. [CrossRef]

8. Morrissy, R.T.; Goldsmith, G.S.; Hall, E.C.; Kehl, D.; Cowie, G.H. Measurement of the Cobb angle on radiographs of patients who have scoliosis. Evaluation of intrinsic error. J. Bone Jt. Surg. Am. 1990, 72, 320-327. [CrossRef]

9. Chockalingam, N.; Dangerfield, P.H.; Giakas, G.; Cochrane, T.; Dorgan, J.C. Computer-assisted Cobb measurement of scoliosis Eur. Spine J. 2002, 11, 353-357.

10. Aroeira, R.M.C.; Estevam, B.; Pertence, A.E.M.; Greco, M.; Tavares, J.M.R.S. Non-invasive methods of computer vision in the posture evaluation of adolescent idiopathic scoliosis. J. Bodyw. Mov. Ther. 2016, 20, 832-843. [CrossRef] [PubMed]

11. Bernstein, P.; Metzler, J.; Weinzierl, M.; Seifert, C.; Kisel, W.; Wacker, M. Radiographic scoliosis angle estimation: Spline-based measurement reveals superior reliability compared to traditional Cobb method. Eur. Spine J. 2021, 30, 676-685. [CrossRef]

12. Chen, K.; Zhai, X.; Sun, K.; Wang, H.; Yang, C.; Li, M. A narrative review of machine learning as promising revolution in clinical practice of scoliosis. Ann. Transl. Med. 2021, 9, 1-16. [CrossRef] [PubMed]

13. Horng, M.-H.; Kuok, C.-P.; Fu, M.-J.; Lin, C.-J.; Sun, Y.-N. Cobb angle measurement of spine from X-ray images using convolutional neural network. Comput. Math. Methods Med. 2019, 2019, 1-18. [CrossRef] 
14. Choi, R.; Watanabe, K.; Jinguji, H.; Fujita, N.; Ogura, Y.; Demura, S.; Kotani, T.; Wada, K.; Miyazaki, M.; Shigematsu, H.; et al. CNN-based spine and Cobb angle estimator using Moire images. IIEEJ Trans. Image Elect. Vis. Comp. 2017, 5, 135-144.

15. Chondro, P.; ul Haq, Q.M.; Ruan, S.-J.; Li, L.P.-H. Transferable architecture for segmenting maxillary sinuses on texture-enhanced occipitomental view radiographs. Mathematics 2020, 8, 768. [CrossRef]

16. Pan, Y.; Chen, Q.; Chen, T. Evaluation of a computer-aided method for measuring the Cobb angle on chest X-rays. Eur. Spine J. 2019, 28, 3035-3043.

17. Carvalho, A.D.; Vialle, R.; Thomsen, L.; Amzallag, J.; Cluzel, G.; le Pointe, H.D.; Mary, P. Reliability analysis for manual measurement of coronal plane deformity in adolescent scoliosis. Are $30 \times 90 \mathrm{~cm}$ plain films better than digitized small films? Eur. Spine J. 2007, 16, 1615-1620. [CrossRef] [PubMed]

18. Accurate Automated Spinal Curvature Estimation (AASCE) 2019 Challenge. Available online: https:/ / aasce19.grand-challenge. org (accessed on 30 August 2021).

19. Caesarendra, W.; Rahmaniar, W.; Mathew, J.; Thien, A. AutoSpine-Net: Spine detection using convolutional neural networks for Cobb angle classification in adolescent idiopathic scoliosis. In Proceedings of the 2nd International Conference on Electronics Biomedical Engineering and Health Informatics (ICEBEHI), Surabaya, Indonesia, 3-4 November 2021.

20. Yi, J.; Wu, P.; Huang, Q.; Qu, H.; Metaxas, D.N. Vertebra-focused landmark detection for scoliosis assessment. In Proceedings of the IEEE 17th International Symposium on Biomedical Imaging (ISBI), Iowa City, IA, USA, 3-7 April 2020; pp. 736-740.

21. Rahmaniar, W.; Wang, W.-J. Real-time automated segmentation and classification of calcaneal fractures in CT images. Appl. Sci. 2019, 9, 3011. [CrossRef]

22. Kaiming, H.; Zhang, X.; Ren, S.; Sun, J. Deep residual learning for image recognition. In Proceedings of the IEEE Conference on Computer Vision and Pattern Recognition (CVPR), Las Vegas, NV, USA, 27-30 June 2016; pp. 770-778.

23. Sinha, S.; Srivastava, U.; Dhiman, V.; PS, A.; Mishra, S. Performance assessment of deep learning procedures: Sequential and ResNet on malaria dataset. J. Robot. Control 2021, 2, 12-18.

24. Oyewola, D.O.; Augustine, A.F.; Dada, E.G.; Ibrahim, A. Predicting impact of COVID-19 on crude oil price image with directed acyclic graph deep convolutional neural network. J. Robot. Control 2021, 2, 103-109.

25. ul Haq, Q.M.; Lin, C.H.; Ruan, S.-J.; Gregor, D. An edge-aware based adaptive multi-feature set extraction for stereo matching of binocular images. J. Ambient Intell. Humaniz. Comput. 2021. [CrossRef]

26. Rahmaniar, W.; Hernawan, A. Real-time human detection using deep learning on embedded platforms: A review. J. Robot. Control 2021, 2, 462-468.

27. Szegedy, C.; Liu, W.; Jia, Y.; Sermanet, P.; Reed, S.; Anguelov, D.; Erhan, D.; Vanhoucke, V.; Rabinovich, A. Going deeper with convolutions. In Proceedings of the IEEE Conference on Computer Vision and Pattern Recognition (CVPR), Boston, MA, USA, 7-12 June 2015; pp. 1-9. 